\title{
SUBMERGED CULTURE CONDITIONS FOR THE PRODUCTION OF MYCELIAL BIOMASS AND ANTIMICROBIAL METABOLITES BY POLYPORUS TRICHOLOMA MONT.
}

\author{
Gladys Rosane Thomé Vieira'*; Mariane Liebl²; Lorena Benathar Ballod Tavares²; Roberta Paulert; \\ Artur Smânia Júnior ${ }^{3}$
}

\begin{abstract}
${ }^{1}$ Departamento de Ciências Naturais, Universidade Regional de Blumenau, Blumenau, SC, Brasil e Programa de Pós-Graduação em Biotecnologia, Universidade Federal de Santa Catarina, Florianópolis, SC, Brasil; ${ }^{2}$ Laboratório de Engenharia Bioquímica, Departamento de Engenharia Química, Universidade Regional de Blumenau, Blumenau, SC, Brasil; ${ }^{3}$ Laboratório de Antibióticos, Departamento de Microbiologia e Parasitologia, Universidade Federal de Santa Catarina, Florianópolis, SC, Brasil.
\end{abstract}

Submitted: November 02, 2007; Returned to authors for corrections: November 22, 2007; Approved: July 13, 2008.

\begin{abstract}
Basidiomycete fungi of the Polyporus genus are a source of secondary metabolites which are of medicinal interest as antibacterial compounds. As these substances are produced in a small amount by the fungi, the study of the cultivation conditions in vitro that could possibly optimize their production seems of major importance. The effects of glucose and lactose, $\mathrm{pH}$ and agitation on biomass concentration and on the specific growth rate caused by the basidiomycete Polyporus tricholoma were investigated. The initial $\mathrm{pH}$ $(4.5,6.5$ and 8.5$)$ was autoregulated at $\mathrm{pH} 5.5$, and the agitation increased the mycelial growth and the specific growth rate. The high concentration of carbon sources (4\%) increased biomass production. The lactose concentration and the absence of agitation were determinant in the production of antibacterial metabolites. The characterization of the antibacterial substance by GC-MS indicated a major compound, isodrimenediol, produced by the fungus Polyporus tricholoma with activity against Staphylococcus aureus.
\end{abstract}

Key-words: Polyporus tricholoma, specific growth rate, antibacterial activity, isodrimenediol.

\section{INTRODUCTION}

Aiming at obtaining bioactive compounds from mushrooms, several researches have tried to cultivate medicinal mushrooms in solid artificial media for fruit body production rather than in submerged cultures for mycelial extract (13). However, submerged cultures have the potential for a higher mycelial production in a shorter period of time within a reduced space if compared to cultivation in solid artificial media. Therefore, it is essential to optimize the fermentation conditions in order to produce biomass and a high rate of compounds with biological and pharmacological activities.

The fungal morphology is an important parameter that influences the mycelial growth rate and the physical properties of the fermentation broth in submerged cultures. The rheological behavior, for instance, is closely related to the morphology and biomass concentration, and it is exactly the broth's rheology that determines the transportation phenomena in bioreactors, which is the key to improve the bioprocess (21). On the other hand, the growth kinetics and the fungal morphology in broth fermentation are highly dependent on the culture conditions, such as carbon sources, $\mathrm{C} / \mathrm{N}$ relation, initial $\mathrm{pH}$ and temperature, agitation intensity and aeration rate (20). A large amount of work has reported the effects of environmental parameters on the biomass concentration and on the yield of bioactive compounds by mushroom, but those researches are limited to few kinds of mushrooms $(4,7,10,12,13,20,25)$.

Polypores constitute a large group of fungi characterized by hymenophores formed by innumerous pores. They belong to the phylum Basidiomycota, and, along with some fungi of

*Corresponding Author. Mailing address: Departamento de Ciências Naturais, Universidade Regional de Blumenau, Blumenau, SC, Brasil e Programa de Pós-Graduação em Biotecnologia, Universidade Federal de Santa Catarina, Florianópolis, SC, Brasil. Tel.: +55-47-3321-7340; fax: +55-47-33216001. E-mail: gladys@furb.br 
the phylum Ascomycota, they are considered as an important source of substances of medicinal interest, such as antibacterial metabolites (27). Polyporus arcularius has been reported to synthesize norsesquiterpene structures, such as drimanes, with antimicrobial activity against Gram-positive bacteria like Staphylococcus aureus (8).

Despite several investigators have studied different antimicrobial fractions from Polyporus, optimal submerged culture conditions have not been extensively determined so far $(3,8,27)$. Then, the present study aimed at optimizing the submerged culture conditions for the production of micelial biomass by two species of Polyporus (P. tricholoma and P. tenuiculus). For a comparative study, a set of fermentations was carried out.

\section{MATERIALS AND METHODS}

\section{Organism and culture conditions}

Two species of fungi were used, Polyporus tricholoma CCB684 and Polyporus tenuiculus CCB-685. Both of them are native from Brazil and belong to the culture collection of basidiomycetes (CCB) of the Botanical Institute of São Paulo (Brazil). The fungi were cultivated in potato dextrose agar (PDA) and, after being isolated, they were maintained at $4^{\circ} \mathrm{C}$ in the same media. The two fungal species were cultivated in $100 \mathrm{~mL}$ of potato dextrose broth (PDB) and MALT medium (malt extract with soy peptone broth/Difco $\left.{ }^{\circledR}\right)$. The flasks of each media were inoculated with five discs of $7 \mathrm{~mm}$ of diameter of fresh mycelium, of the species $P$. tenuiculus and P. tricholoma, on PDA in separated experiments. The flasks were incubated at $25^{\circ} \mathrm{C}$, under aerobic conditions, in the absence of light, for a period up to 30 days and the tests were carried out in triplicate. During this period, the biomass $(\mathrm{g} / \mathrm{L}), \mathrm{pH}$ values and antibacterial activity were determined after every 5 days of cultivation.

\section{Optimization of the cultivation conditions}

For optimization tests only $P$. tricholoma was used. Twenty plugs of mycelium in PDA were added to $400 \mathrm{~mL}$ of $2.4 \%$ PDB with $1 \%$ malt extract and $0.1 \%$ soy peptone. The culture was incubated at $25^{\circ} \mathrm{C}$ for 5 days. Afterwards, $10 \mathrm{~mL}$ of culture were transferred to flasks containing $90 \mathrm{~mL}$ of the $2.4 \%$ PDB and $0.1 \%$ malt extract (MP broth) as culture media. The cultures were incubated at $25^{\circ} \mathrm{C}$, under aerobic condition, in the absence of light, for 15 days. During this step it was studied the following parameters: initial $\mathrm{pH}: 4.5 ; 6.5 ; 8.5$; agitation: $150 \mathrm{rpm}$ and absence of agitation; lactose: 1 and $4 \%$. In later tests the $\mathrm{pH}$ value of 4,5 was maintained and glucose in concentrations of 1 and $4 \%$ was also tested.

\section{Determination of cell dry mass}

In order to determine the fungal biomass at specific time intervals, the mycelium was filtered through filter paper
(Whatman $\mathrm{n}^{\circ} 40$ ), washed with distilled water and dried at constant weight at $80^{\circ} \mathrm{C}$. The mycelium was placed in the desiccator and then the mass was determined.

\section{Specific growth rate}

Aiming at determining the specific growth rate $(\mu)$, natural log of biomass $(\ln \mathrm{X})$ was plotted against time $(\mathrm{t})$. The slope of the line at any moment gives the specific growth rate at each moment.

\section{Extraction and characterization of antibacterial metabolites}

The mycelium was removed through filtration and the metabolites, present in the filtrates, were extracted with ethyl acetate, concentrated in a rotavapor and the residue was weighted. The extract in ethyl acetate was characterized by GCMS $(70 \mathrm{eV})$, performed in a Varian Saturn $2000 \mathrm{GC} / \mathrm{MS}$ spectrometer in split injector mode. A CP-Sil-8CB capillary column ( $30 \mathrm{~m} \mathrm{x} 0.25 \mathrm{~mm}, 0.25 \mathrm{~mm}$ film thickness) was operated at $60^{\circ} \mathrm{C}$ for $3 \mathrm{~min}$, and then programmed for $60^{\circ}-220^{\circ} \mathrm{C}$ at $5^{\circ} \mathrm{C} / \mathrm{min}$, after which it was kept isothermal at $220^{\circ} \mathrm{C}$ for $5 \mathrm{~min}$. The carrier gas was helium and the injector temperature was of $250^{\circ} \mathrm{C}$. The components of the extract were identified by comparison of fragmentation patterns in mass spectra with those stored on the spectrometer database and reported in the literature. The relative percentage of individual components was calculated from the GC peak areas.

\section{Antibacterial activity tests}

Overnight cultures of Staphylococcus aureus ATCC 25923 and Escherichia coli ATCC 25922 strains were diluted to a final concentration of $10^{8} \mathrm{CFU} / \mathrm{mL}$. The bacterial suspensions were spread over the surface of Mueller-Hinton agar, containing five wells of $7 \mathrm{~mm}$ of diameter. The wells were filled with $50 \mu \mathrm{l}$ of both extracts $(5 \mathrm{mg})$ which were dissolved in $50 \mu$ l of dimethilsulfoxid (DMSO). The chloramphenicol disks ( $30 \mu \mathrm{g})$ and $50 \mu \mathrm{l}$ of DMSO were used as controls. The plates were incubated at $37^{\circ} \mathrm{C}$ for 24 hours. The reading was carried out by measuring the growth inhibition zones, and a halo greater than $9 \mathrm{~mm}$ was considered positive. In order to evaluate the minimum inhibitory concentration (MIC), the total amount of the extracts dissolved in DMSO was diluted in Mueller Hinton broth and dispensed into each microplate well. The bacterial suspension in a concentration of $10^{8} \mathrm{CFU} / \mathrm{mL}$ was inoculated in the plate and incubated at $37^{\circ} \mathrm{C}$ for 24 hours. The reading was carried out using an ELISA reader, at $630 \mathrm{~nm}$, and it was performed with $\rho$ iodonitrotetrazolium violet (INT) (22).

\section{RESULTS AND DISCUSSION}

\section{Influence of the carbon and nitrogen sources on the growth of the Polyporus}

To investigate the effects of nitrogen and carbon sources over mycelial growth, two kinds of culture media were examined 
(Fig. 1). Neither the mycelial concentration of P. tenuiculus, nor the growth rate were influenced by the media as long as very low values $(0,066 \mathrm{~g} / \mathrm{L}$.day $)$ were found, if compared to the ones obtained for the other strain $(0,83 \mathrm{~g} / \mathrm{L}$.day $)$. On the other hand, the medium containing glucose (PDB) provided a lower growth to the strain P. tricholoma, in comparison to the MALT medium. In fact, it was possible to notice a significant difference in the biomass production of $P$. tricholoma in the inoculated media. This result reflects both the effect of nitrogen and the specie over the mycelial growth. A significant growth of Psathyrella atroumbonata was obtained when it was used malt extract and L-triptofano while in the medium with sodium nitrate and ammonium sulphate the mycelial production presented the worst result. The stimulating effect of the two organic sources can be attributed to their carbon and nitrogen content (12). Despite the fact that both the malt extract and the corn juice are used as nitrogen sources, they are also carbon sources. The nitrogen content of the corn juice is of $6,7 \%$ and the carbon content is of $36,3 \%$ in dry weight. As the fungi have efficient enzymatic systems, they can easily break molecules more complex than glucose for their development (14).

The maximum rate of mycelial growth $(\mu)$ of $P$. tenuiculus (Table 1) was similar in both media $\left(0,022 \mathrm{dya}^{-1}\right)$, as well as the cellular productivity (Px). The specific growth velocity showed a short increase in the PDB medium, while in the medium containing nitrogen (MALT) it was observed an exponential increase in the mycelial growth, followed by the stationary phase, after the thirteenth day of cultivation.

\section{Correlations between kinetics growth rate, substrate and antibacterial activity}

The antibacterial activity of the two species that were used in the medium is shown in Fig. 2. The production of antibacterial
Table 1. Kinetic parameters of Polyporus tricholoma and Polyporus tenuiculus cultivation in Malt and PDB media.

\begin{tabular}{cccc}
\hline Medium & & $\mu_{\mathrm{Xmax}}\left(\mathrm{day}^{-1}\right)$ & $\begin{array}{c}\mathrm{P}_{\mathrm{X}}\left(\mathrm{g} . \mathrm{L}^{-1} \mathrm{day}^{-1}\right) \\
\text { Exponential step }\end{array}$ \\
\hline Malt & P. tricholoma & 0.082 & 0.878 \\
PDB & & 0.021 & 0.324 \\
Malt & P. tenuiculus & 0.006 & 0.000 \\
PDB & & 0.003 & 0.000 \\
\hline
\end{tabular}

substances by $P$. tenuiculus was not detected in any of the cultivation media in relation to the bacteria which was being tested. According to the studies developed by Cabrera et al. (3), tests of the activity of this fungus against the same bacteria that was used in this study were also negative. The fungus $P$. tricholoma did not show activity against Escherichia coli in the agar diffusion test; however, it showed activity against Staphylococcus aureus, in both cultivation media, after the $13^{\text {th }}$ day of incubation. The growth inhibition halos of $S$. aureus, which point out the presence of the antibacterial substance in the fungic extracts of the MALT medium, were higher than the ones of the PDB medium. These results may be explained by the fact that the medium used was a source of organic nitrogen. The soy peptone used in the production of actinomycete antibiotics has the advantage of being slowly metabolized and, therefore, repressive ammonia salts and aminoacids do not accumulate (17). When establishing a relation with the phases of the mycelial growth curve, it was observed that the most pronounced inhibition took place in the stationary phase present in the MALT medium, and the inhibitory activity occurred

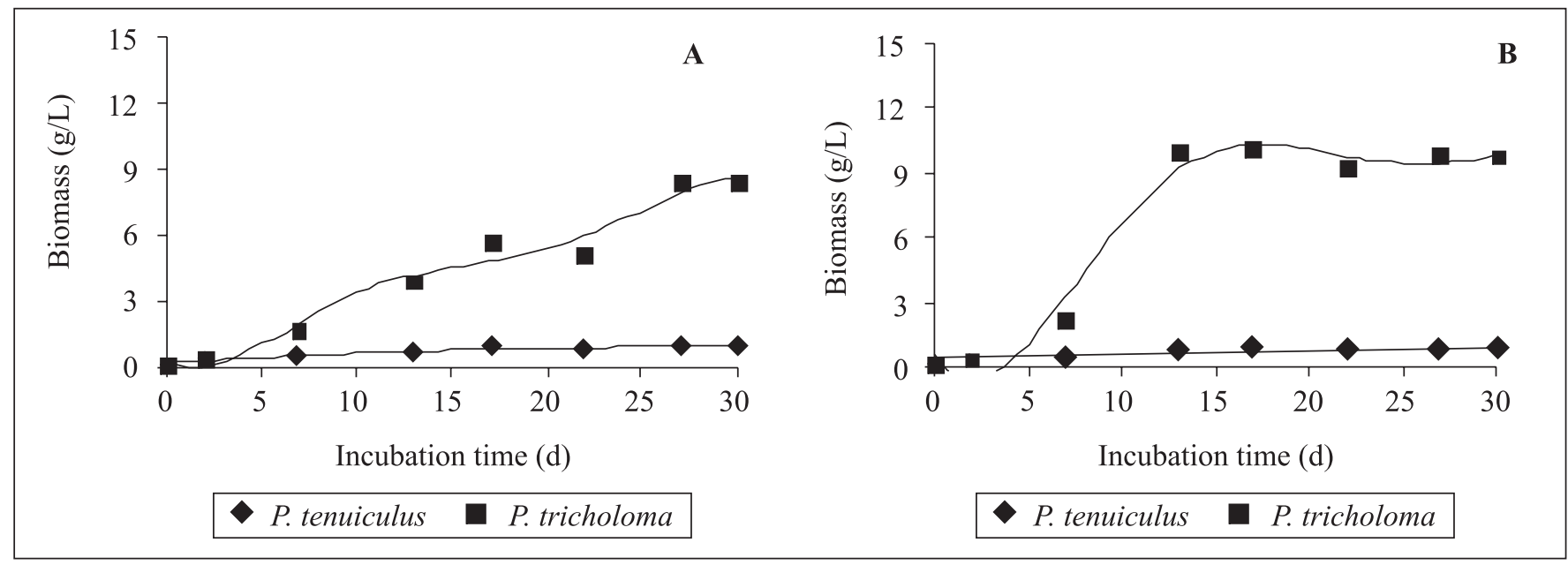

Figure 1. Effect of PDB (A) and MALT media (B) on mycelial growth of Polyporus tricholoma and Polyporus tenuiculus. 
during the same growth interval, independently of the media. It can possibly be an indication that the production of the substance takes place when the average growth velocity is low or constant. These results show that the best growth is not always correlated with a greater production of the secondary metabolite. Bu'Lock (2) called the period of secondary metabolite production as idiophase due to the special nature (idiosyncratic) of the products.

The influence of $\mathrm{pH}$ in the synthesis of antimicrobial compounds is a factor that has been described using different fungic species. In the present work, the $\mathrm{pH}$ did not influence the production of the secondary metabolite. However, there was a statistical difference in the case of $P$. tricholoma extracts when the MALT medium was used and at 17 days and 22 days of cultivation (Fig. 2).

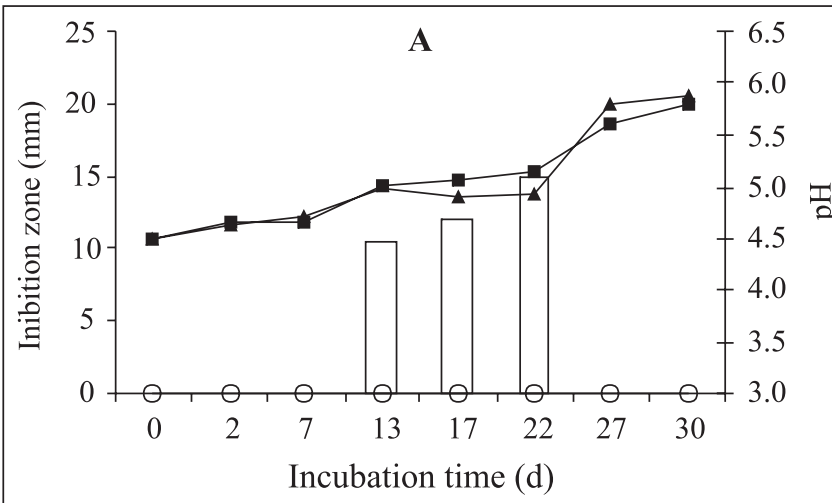

\begin{tabular}{|l|l|}
$\square$ \\
$\square$ Inibition zones $P$. tricholoma & $-p H$ P. tricholoma \\
- pH P. tenuiculus & - Inibition zones P. tenuiculus
\end{tabular}

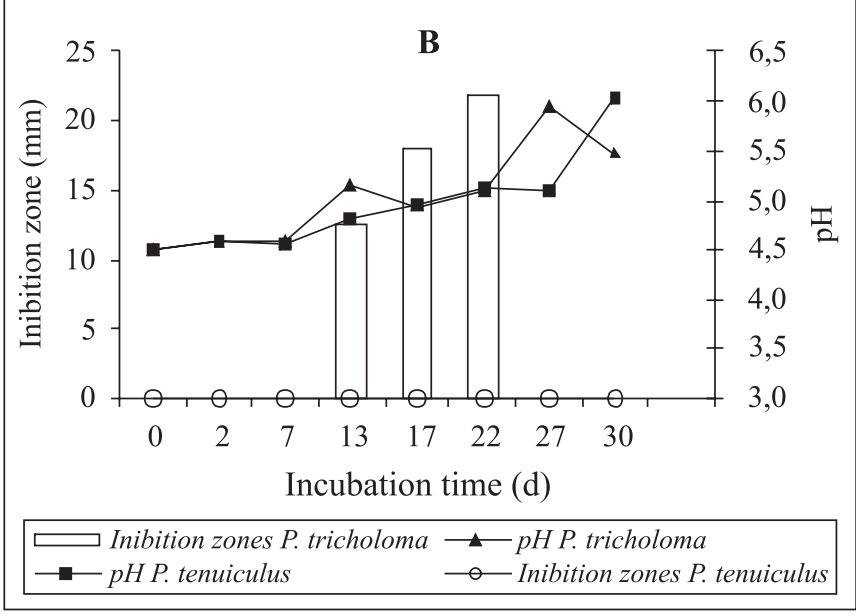

Figure 2. Average diameters of the growth inhibition halos (mm) of Staphylococcus aureus, using Polyporus tricholoma and Polyporus tenuiculus in potato dextrose broth (A) and malt extract with peptone broth (B).

\section{Culture conditions for the production of biomass and antibacterial metabolite}

In the cultivation of $P$. tricholoma with different concentrations of the carbon sources, $\mathrm{pH}$ and agitation, it was observed that there was an average adjustment of the medium $\mathrm{pH}$ to values close to 5,5 (Fig. 3). Regardless the initial pH and other factors, there was an average adjustment of the $\mathrm{pH}$ for final cultivation values of 5.0 and 6.0. Some species of fungus show the characteristic of autoregulating the substrate $\mathrm{pH}$, stabilizing it at the value that is considered optimum for its development (19).

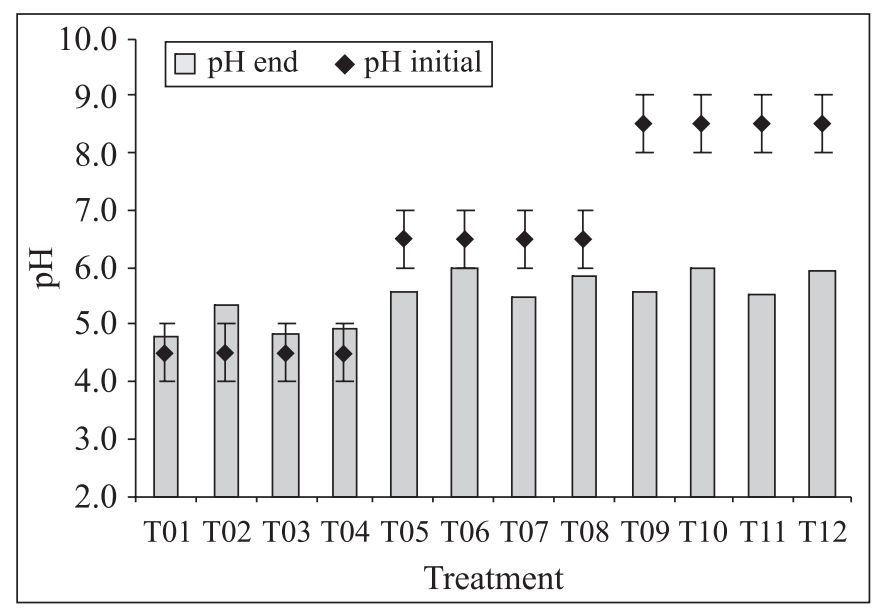

Figure 3. Average variations of cultivation $\mathrm{pH}$ using Polyporus tricholoma, under different process conditions, for 15 days of cultivation. T1 to T4: $\mathrm{pH} 4.5$; T5 to T8: $\mathrm{pH} 6.5$; T9 to T12: $\mathrm{pH} 8.5$. Lactose 1\%: T1, T2, T5, T6, T9, T10. Lactose 4\%: T3, T4, T7, T8, $\mathrm{T} 11$ and $\mathrm{T} 12$.

$\mathrm{T} 1 ; \mathrm{T} 3 ; \mathrm{T} 5 ; \mathrm{T} 7 ; \mathrm{T} 9 ; \mathrm{T} 11=$ no agitation; T4; T6; T8; T10; T12= agitation)

The inhibitory property of the fungus $P$. tricholoma was evaluated under different cultivation conditions, against $S$. aureus. Fungal metabolites were extracted with ethyl acetate and they were tested through the diffusion method. Positive results were observed for the treatments described in Fig. 4.

The statistical analysis revealed that all factors $(\mathrm{pH}$, lactose concentration and agitation) influenced $(p<0.05)$ the production of antimicrobial substances by $P$. tricholoma, besides indicating a significant interaction between those factors. However, the factor which showed the greatest isolated effect was the lactose concentration. The antimicrobial activity increased with the increase in the concentration of this carbohydrate. For fermentation processes aiming the production of secondary metabolites, it seems better to use polysaccharides, such as 


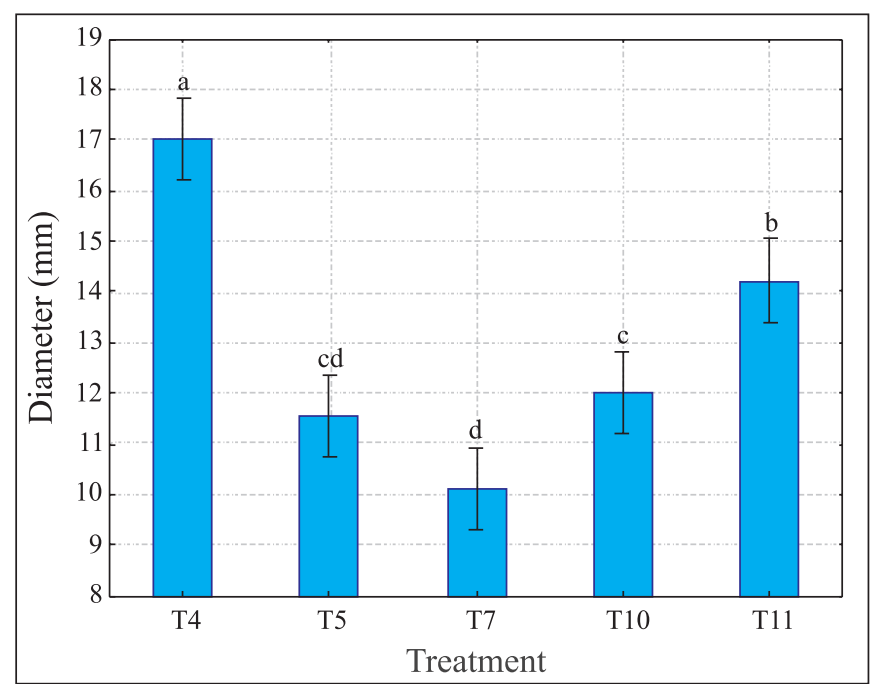

Figure 4. Average diameters of the growth inhibition halos (mm) of Staphylococcus aureus using Polyporus tricholoma in the treatments T4 (pH 4.5; lactose 4\%; with agitation); T5 (pH 6.5; lactose $1 \%$; without agitation); T7 (pH 6.5; lactose 4\%; without agitation); $\mathrm{T} 10$ (pH 8.5; lactose $1 \%$; with agitation) and $\mathrm{T} 11(\mathrm{pH}$ 8.5 ; lactose $4 \%$; without agitation), after 20 days. The bars denote a confidence interval of $95 \%$ and the treatments with the same letters did not differ according to the Tukey test at 5\% probability.

starch; oligosaccharides, such as lactose, and oils such as soy oil $(1,5)$. An increase in the biomass and Tremella mesenterica exopolysaccharides occurred when there was an increase in the initial concentrations of sucrose from 1 to $6 \%(7)$. The greater number of cultures without agitation inhibited the bacterial growth; however, treatment 4, under agitation at $150 \mathrm{rpm}$, gave the largest halo. Some authors report the production of pellets, which may be caused by agitation, as being a good event to promote the production of antibiotics and other metabolites. The production of citric and itaconic acids by Aspergillus niger was increased when the fungus showed the morphology which is mentioned above (6). On the other hand, disperse growth is preferable for the production of penicillin by Penicillium chrysogenum (23), and cephalosporin by Cephalosporium acremonium (18).

By analyzing the different initial $\mathrm{pH}$ values used in the treatments, it is possible to notice that they show to have an isolated effect of synergistic nature over the other studied factors. Higher initial $\mathrm{pH}$ values were shown to have better effects over the antimicrobial metabolites production, as it was demonstrated by Smânia et al. (22) for the production of the antibacterial cinnabarin. However, an initial medium $\mathrm{pH}$ of 5,5 improved the production of biomass and exopolysaccharides by Grifola frondosa (13).
Effect of agitation and carbohydrate concentration over the production of biomass and antibacterial metabolite

The mycelial growth of $P$. tricholoma was higher for the cultivations under agitation than for static cultivations. There was a significant difference $(\mathrm{p}<0.05)$, when analyzing the biomass values over the time. It can be seen that the treatments with the highest concentration of carbohydrates, T3 and T4 (glucose 4\%), T7 and T8 (lactose 4\%), resulted into the greatest growth, and lactose showed to be the best source of carbon for the mycelial production (Fig. 5).

There is a higher cellular growth for treatments under agitation than for those which are kept static. On the other hand, there was no significant interaction with the carbohydrate concentration. The cell production was due to the homogenization and heat transference when physical and chemical conditions are maintained homogenous and more oxygen becomes available (16). An agitation at $50 \mathrm{rpm}$ was used to increase the production of biomass and polysaccharides by Phellinus linteus (10), while for the culture conditions of polypore Antrodia cinnamomea an agitation of $100 \mathrm{rpm}$ increased the mycelial growth (26).

Table 2 summarizes the effect of agitation over the specific growth velocity of $P$. tricholoma with carbon sources (glucose and lactose). The maximum specific growth velocity and the productivity in cells increased with agitation.

The antibacterial activity of the extracts against the bacteria S. aureus started only on the $14^{\text {th }}$ day (Fig. 6). The statistical analysis for the $21^{\text {st }}$. day, when the largest halos were obtained, shows that there are differences between treatments T2, T4 and T7. Those differences are connected to the best source of carbon for growth and the one that promotes the production of secondary metabolites. Glucose, which is an excellent source of carbon for growth, depresses the synthesis of a series of metabolites such as actinomycin and cephalosporin. However, it does not interfere in the production of aminoglycosides and chloramphenicol (15).

Table 2. Agitation effect on Polyporus tricholoma growth under different treatments.

\begin{tabular}{cccc}
\hline Treatments & & $\mu_{\text {Xmax }}\left(\right.$ day $\left.^{-1}\right)$ & $\begin{array}{c}\mathrm{P}_{\mathrm{X}}(\mathrm{g} . \mathrm{L} \text { day } \\
\text { Exponential step }\end{array}$ \\
\hline 01 & with & 0.102 & 0.323 \\
03 & agitation & 0.156 & 0.645 \\
05 & & 0.166 & 0.549 \\
07 & & 0.107 & 0.641 \\
02 & without & 0.072 & 0.169 \\
04 & agitation & 0.094 & 0.359 \\
06 & & 0.067 & 0.173 \\
08 & & 0.076 & 0.337 \\
\hline
\end{tabular}




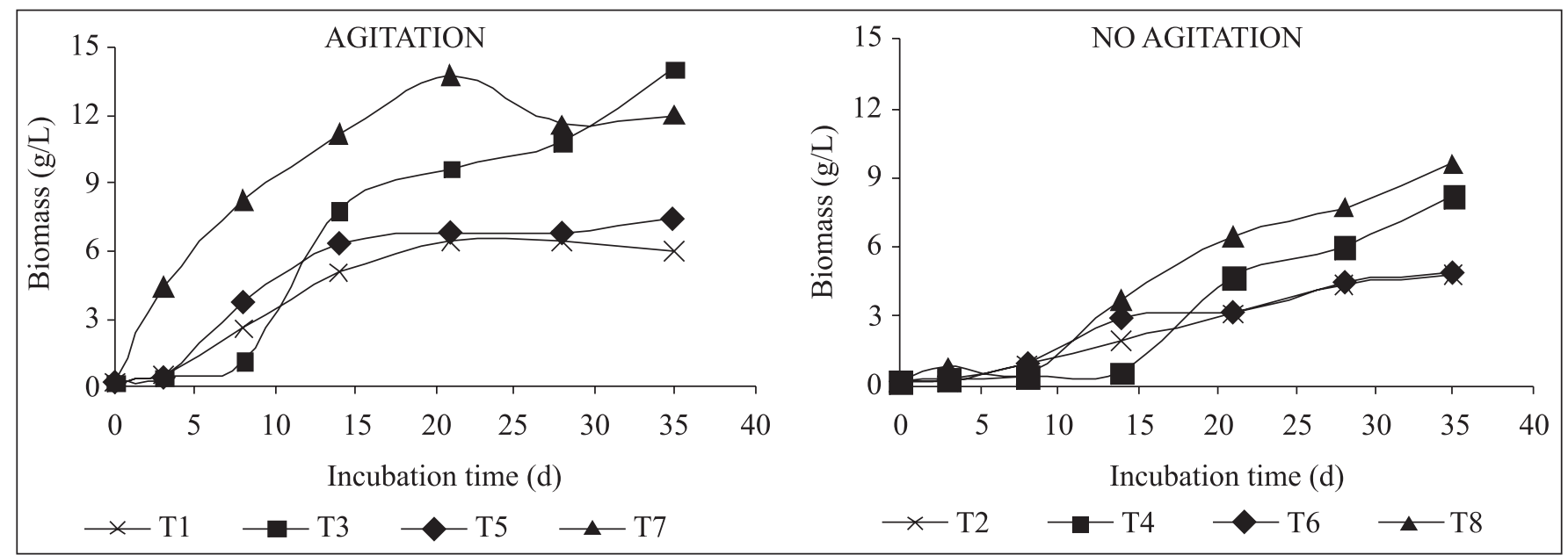

Figure 5. Growth curve of Polyporus tricholoma in potato dextrose broth and $1 \%$ of peptone malt extract, cultivated at $25^{\circ} \mathrm{C}, \mathrm{pH}$ 4,5, for 35 days, in treatments: T1 and T2 (1\% glucose), T3 and T4 (4\% glucose), T5 and T6 (1\% lactose) and T7 and T8 ( $4 \%$ lactose).

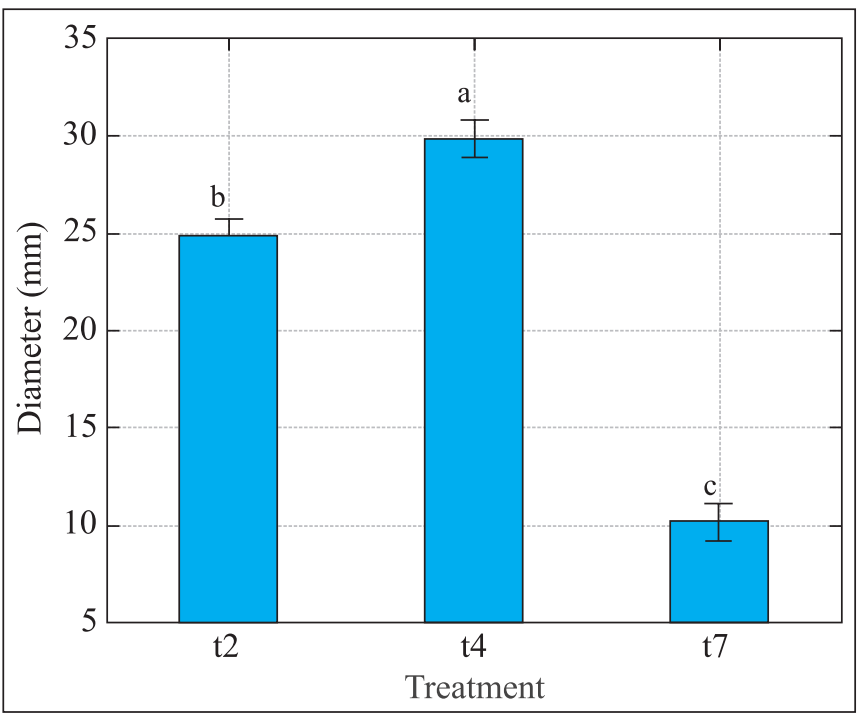

Figure 6. Average inhibition halos (mm) of Staphylococcus aureus using Polyporus tricholoma at a cultivation time of 21 days, for the treatments: T2 (glucose $1 \%$, without agitation), T4 (glucose $4 \%$, without agitation), T7 (lactose $4 \%$, with agitation). Average data with different letters differ statistically according to the Tukey test at a $5 \%$ probability.

Along with glucose, other carbon sources and other medium nutrients may depress the synthesis of antibiotics (17). A comparative study using various carbohydrates showed that lactose is the best source of carbon for the promotion of mycelial growth and for the production of ganoderic acid and polysaccharides in the case of Ganoderma lucidum (25). For the cultivation conditions which were used, and from the obtained results, it can be seen that the global physiological regulation is very complex due to the diversity of fungi and the variety of metabolic pathways and controls (24).

\section{Characterization of the antibacterial substance}

Spectral data of the ethyl acetate extract showed the presence of a sesquiterpenic structure of the drimanes class (Fig. 7). The main product had a relative concentration of $29.49 \%$ with a retention time of $32.941 \mathrm{~min}$. It was present between $\mathrm{C}_{20}$ (R.T. $32.506 \mathrm{~min}$ ) and $\mathrm{C}_{21}$ (R.T. $34.354 \mathrm{~min}$ ) and it was identified by the NIST 98 MS Library as Isodrimenediol $\left(\mathrm{C}_{15} \mathrm{H}_{26} \mathrm{O}_{2}\right)$ (5-Hydroximethyl-1,1,4a-trimethyl-6-methylenedecahydronaphtalen-2-ol). The characterization by EIMS (70 $\mathrm{eV})$ showed $m / z(\%)=238\left(\mathrm{M}^{+}, 1\right) ; 220\left(\mathrm{M}^{+}-\mathrm{H}_{2} \mathrm{O}, 8\right) ; 202\left(\mathrm{M}^{+}-\right.$ $\left.2 \mathrm{H}_{2} \mathrm{O}, 12\right) ; 187$ (18); $176(16) ; 152(23) ; 135$ (100); 119 (28); 107 (63); 91 (43); 79 (39); 67 (24); 55 (13).

The isodrimenediol, which was here isolated from $P$. tricholoma, was described by Fleck at al., when obtained from the species Polyporus arcularius (8), as a biosynthesis intermediate of the drimanes norsesquiterpenes of this fungus. The isolation of these compounds from a fungal strain which also produces other drimane-type structures, indicates that these compounds may be biosynthesized via isodrimenediol as an intermediate. The total extract was used to evaluate the minimum inhibitory concentration (MIC) and the result for the S. aureus was of $1,0 \mathrm{mg} / \mathrm{mL}$. The moderate activity of isodrimenediol and 7-drimano-3,11,12-triol against Gram-positive bacteria such as Staphylococcus aureus SG511, and yeasts such as Sporobolomyces salmonicolor 549 was reported by Fleck et al. (8). Recent studies have revealed new sesquiterpenes, the isocriptoporic $\mathrm{H}$ and I acids obtained from P. arcularius, while 


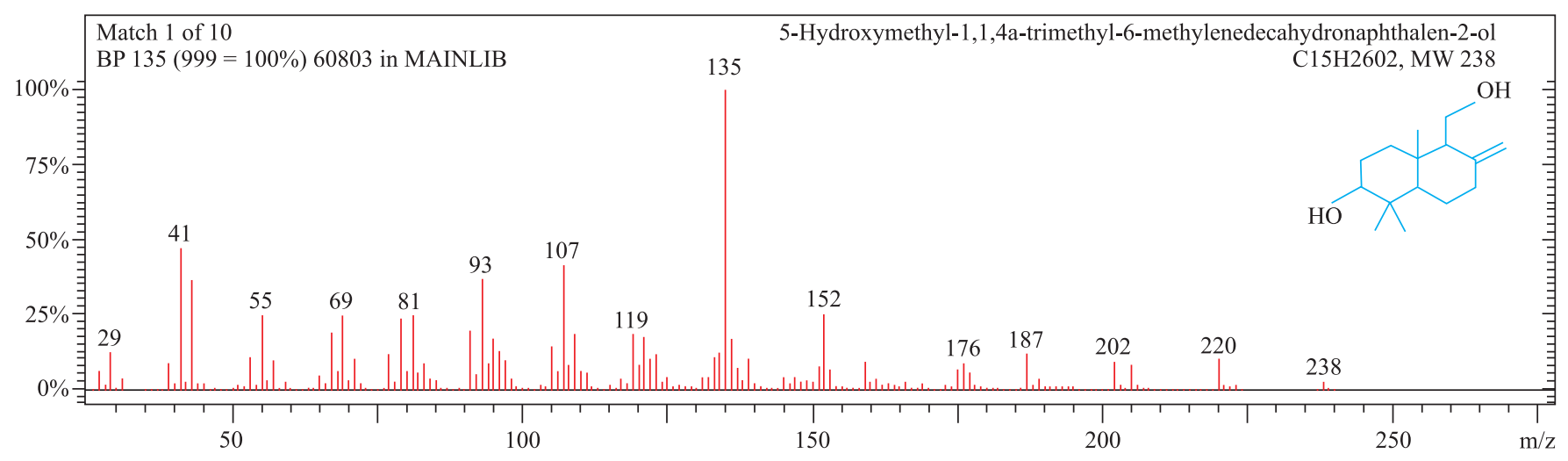

Figure 7. Mass Spectrum results for the major compound (T. R. $32.939 \mathrm{~min}$ ) and proposal for the structure obtained from the NIST 98 MS Library. Saturn ${ }^{\circledR} 2000$ Mass Spectrometer.

the criptoporic $\mathrm{H}$ acid and its methyl ester have been found in Polyporus ciliatus (3). There is the hypothesis that the three terpene alcohols, grouped in the farnesane group, act on the cellular membrane of $S$. aureus (11). Isodrimenediol is an intermediate of the biosynthesis of terpenes of the bicyclofarnesane group (9). Since the chemical structures of the two groups are similar, there is a possibility that the action mechanism of isodrimenediol over $S$. aureus follows the model described for the farnesane group.

In conclusion, the results indicate that the production of biomass of $P$. tricholoma in MALT medium is higher than the production of biomass of $P$. tenuiculus. The antibacterial activity was observed for the Gram-positive Staphylococcus aureus in the stationary phase, with the MIC of $1,0 \mathrm{mg} / \mathrm{mL}$. The agitation and the higher concentration of carbohydrates incresead the biomass, but the treatments which are kept static, with $4 \%$ of lactose, showed the best antibacterial activity.

\section{ACKNOWLEDGEMENTS}

We hereby thank Marina Capelari and Adriana Gugliotta, researchers of the São Paulo Institute of Botany, for kindly providing the fungus species used in the study.

\section{RESUMO}

\section{Condições de cultivo em meio líquido para produção de biomassa e metabólitos antibacterianos por Polyporus tricholoma Mont}

Os fungos basidiomicetos do gênero Polyporus são fonte de metabólitos secundários de interesse medicinal como os compostos antibacterianos. Como estas substâncias são produzidas em pequenas quantidades pelos fungos, o estudo de condições de cultivo in vitro que otimizem sua produção, é de fundamental importância. Os efeitos da glicose e lactose, $\mathrm{pH}$ e agitação na concentração da biomassa e na velocidade específica de crescimento realizada pelo basidiomiceto Polyporus tricholoma foram investigados. $\mathrm{O}$ pH inicial $(4.5,6.5$ e 8.5) foi autoregulado para $\mathrm{pH} 5.5$, e a agitação aumentou o crescimento micelial e a velocidade específica de crescimento. A maior concentração das fontes de carbono (4\%) incrementou a produção de biomassa. A concentração de lactose e a ausência de agitação foram determinantes na produção dos metabólitos antibacterianos. A caracterização da substância antibacteriana por CG-EM mostrou como componente majoritário o isodrimenediol, produzido pelo fungo Polyporus tricholoma, com atividade contra Staphylococcus aureus.

Palavras-chave: Polyporus tricholoma, velocidade específica de crescimento, atividade antibacteriana, isodrimenediol.

\section{REFERENCES}

1. Adrio, J.L.; Demain, A.L. (2003). Fungal Biotechnology. Int. Microbiol., 6 (3), 191-199.

2. Bu'lock, J.D. (1967). Essays in biosynthesis and microbial development. Wiley-Liss, New York, USA.

3. Cabrera, G.M.; Roberti, M.J.; Wright, J.E.; Seldes, A.M. (2002). Cryptoporic and isocryptoporic acids from the fungal cultures of Polyporus arcularius and P. ciliatus. Phytochemistry, 61, 189-193.

4. Cavallazzi, J.R.P.; Kazuya, C.M.; Soares, M.A. (2005). Screening of inducers for laccase production by Lentinula edodes in liquid medium. Braz. J. Microbiol., 36, 383-387.

5. Demain, A.L. (1996). Fungal secondary metabolism: regulation and functions. In: Sutton, B. A Century of Mycology. Cambridge University Press, Cambridge, England, p. 233-254.

6. El-Enshasy, H.; Hellmuth, K.; Rinas, U. (1999). Fungal morphology in submerged cultures and its relation to glucose oxidase excretion by recombinant Aspergillus niger. Appl. Biochem. Biotechnol., 81, 1-11.

7. Elisashvili, V.; Wasser, S.P.; Tan, K.K. (2003). Effects of carbon and nitrogen sources in the medium on Tremella mesenterica Retz. Fr (Heterobasidiomycetes) growth and polysaccharide production. Int. J. Med. Mushrooms, 5 (1), 48-56. 
8. Fleck, W.F.; Schlegel, B.; Hoffmann, P.; Ritzau, M.; Heinze, S.; Gräfe, U. (1996). Isolation of isodrimenediol, a possible intermediate of drimane biosynthesis from Polyporus arcularius. J. Nat. Prod., 9, 780-781.

9. Fraga, B.M. (2003). Natural sesquiterpenoids (Review). Nat. Prod. Rep., 20, 392-413.

10. Hwang, H.J.; Kim, S.W.; Choi, J.W.; Yun, J.W. (2003). Production and molecular characteristics of four groups of exopolysaccharides from submerged culture of Phellinus gilvus. J. Appl. Microbiol., 94, 708-719.

11. Inoue, Y.; Shiraishi, A.; Hada, T.; Hirose, K.; Hamashima, H.; Shimada, J. (2004). The antibacterial effects of terpene alcohols on Staphylococcus aureus and their mode of action. FEMS Microbiol. Lett., 237, 325-331.

12. Jonathan, S.G.; Fasidi, I.O. (2001). Effect of carbon, nitrogen and mineral sources on growth of Psathyrella atroumbonata (Pegler), a Nigerian edible mushroom. Food Chem., 72, 479-483.

13. Lee, B.C.; Bae, J.T.; Pyo, H.B.; Choe, T.B.; Kim, S.W.; Hwang, H.J.; Yun, J.W. (2004). Submerged culture conditions for the production of mycelial biomass and exopolysaccharides by the edible basidiomycete Grifola frondosa. Enzyme Microb. Technol., 35, 369-376.

14. López, J.L.C.; Pérez, J.A.S.; Sevilla, J.M.F.; Fernández, F.G.A.; Grima, E.M.; Chisti, Y. (2003). Production of lovastatin by Aspergillus terreus: effects of the C:N ratio and the principal nutrients on growth and metabolite production. Enzyme Microb. Technol., 33, 270-277.

15. Luchese, R.; Harrigan, W. (1993). Biosynthesis of aflatoxin- the role of nutricional factors. J. Appl. Bacteriol., 74, 5-14.

16. Mantzouridou, F.; Roukas, T.; Kotzekidou, P. (2002). Effect of the aeration rate and agitation speed on $\beta$-carotene production and morphology of Blakeslea trispora in a stirred tank reactor: mathematical modeling. Biochem. Eng. J., 10, 123-135.

17. Martin, J.F.; Demain, A.L. (1980) Control of antibiotic biosynthesis. Microbiol. Rev., 44, 230-251.
18. Queener, S.W.; Ellis, L.F. (1975). Differentiation of mutants of Cephalosporium acremonium in a complex médium: the formation of unicellular arthrospores and their germination. Can. J. Microbiol., 21, 1981-1996.

19. Santos, E. (2001). Produção de xilanases por Thermoascus aurantiacus ATCC 204492 em cultivo semi-sólido utilizando bagaço de cana de açúcar. Dissertation. Faculdade de Engenharia Química de Lorena, São Paulo (Brasil).

20. Shu, C.H.; Lin, K.J.; Wen, B.J. (2004). Effects of culture pH on the production of bioactive polysaccharides by Agaricus blazei in batch cultures. J. Chem. Technol. Biotechnol., 79, 998-1002.

21. Sinha, J.; Bae, J.T.; Park, J.P.; Song, C.H.; Yun, J.W. (2001). Effect of substrate concentration on broth rheology and fungal morphology during exo-biopolymer production by Paecilomyces japonica in a batch bioreactor. Enzyme Microb. Technol., 29 (6,7), 392-399.

22. Smânia, A.Jr.; Delle Monache, F.; Smânia, E.F.A.; Gil, M.L.; Benchetrit, F.S.; Cruz, F.S. (1995). Antibacterial activity of a substance produced by the fungus Pycnoporus sanguineus (Fr) Murr. $J$. Etnopharmacology, 45, 177-181.

23. Smith, J.J.; Lilly, M.D.; Fox, R.I. (1990). The effect of agitation on the morphology and penicillin production of Penicillium chrysogenum. Biotechnol. Eng., 35, 1011-1023.

24. Spízek, J.; Tichy, P. (1995). Some aspects of overproduction of secondary metabolites. Folia Microbiol., 40 (1), 43-50.

25. Tang, Y.J.; Zhong, J.J. (2002). Fed-batch fermentation of Ganoderma lucidum for hyperproduction of polysaccharide and ganoderic acid. Enzyme Microb. Technol., 31, 20-28.

26. Yang, F.C.; Huang, H.C.; Yang, M.J. (2003). The influence of environmental conditions on the mycelial growth of Antrodia cinnamomea in submerged cultures. Enzyme Microb. Technol., 33, 395-402.

27. Zjawiony, J.K. (2003). Biologically active compounds from Aphyllophorales (Polypore) fungi. J. Nat. Prod., 61, 1053-1071. 